\title{
Thrombospondin Production and Thrombospondin-Mediated Adhesion in U937 Cells
}

\author{
J. Varani, ${ }^{1}$ L. Stoolman, T. Wang, ${ }^{2}$ L. Schuger, C. Flippen, M. Dame, K. J. Johnson, \\ R. F. TODD III, U. S. RYAN, AND P. A. WARD \\ The Departments of Pathology and Internal Medicine, The University of Michigan Medical School, Ann Arbor, Michigan 48109; \\ and Monsanto Corporation, 700 Chesterfield Parkway, Chesterfield, Missouri 63198
}

U937 cells have low levels of surface thrombospondin (TSP) under control conditions but express higher levels after treatment for 1 day with $100 \mathrm{nM}$ phorbol myristate acetate (PMA). Increased surface expression is due, in part, to increased biosynthesis. Untreated U937 cells do not adhere to TSP-coated plastic culture dishes but adhere strongly to TSP after stimulation with PMA. Untreated U937 cells also adhere weakly to endothelial cell monolayers while PMA-treated U937 cells attach strongly to monolayers of rat pulmonary artery endothelial cells. Fndothelial cell adhesion appears to be mediated, in part, by TSP since antibodies to TSP partially inhibit. 1991 Academic Press, Inc.

\section{INTRODUCTION}

Thrombospondin (TSP) is synthesized by a variety of cells in culture [1-6] and serves as an adhesion factor for many of the same cells [5, 7-10]. Our studies have shown a direct relationship between TSP synthesis and TSP binding among squamous epithelial cells $[5,7,10$. 12]. This provides a mechanism whereby the endogenously synthesized TSP may be used in an autocrine fashion to promote cell-substrate adhesion. In epithelial cells, TSP synthesis is related to the growth cycle. Rapidly proliferating, undifferentiated cells synthesize large amounts of TSP while synthesis is decreased greatly during differentiation $[5,10]$. This is consistent with the suggestion that TSP has an important function in epithelial growth. In support of this is the finding that TSP is localized in vivo to sites where epithelial cells are rapidly proliferating (i.e., in the basal cell layer of skin and around hair follicles) [13]. A direct role for TSP in smooth muscle cell proliferation $[14,15]$ and fibroblast proliferation has also been shown [16].

\footnotetext{
${ }^{1}$ To whom reprint requests should be addressed at: Department of Pathology, University of Michigan Medical School, 1301 Catherine Road, Box 0602, Ann Arbor, MI 48109.

${ }^{2}$ Current address: China-Japan Friendship Hospital, Yinghua East Road, Hepingli, Choyang District 100013, Beijing, PRC.
}

Past studies have demonstrated that monocytes synthesize TSP in culture $[17,18]$. However, monocytes do not actively proliferate in culture and the relationship between TSP synthesis and monocyte function is unknown. To address this question, we have utilized the monocyte-like line U937. This cell line was originally derived from a histiocytic lymphoma and expresses many of the characteristics of monocytes [19]. U937 cells can be induced by a variety of agents to differentiate into cells with characteristics of mature macrophages [20]. We report here that U937 cells produce small amounts of TSP when unstimulated but synthesize greatly increased amounts of TSP after treatment with phorbol esters. Concomitant with this is up-regulation of adhesion to TSP as well as to vascular endothelial cells of rat origin. That TSP produced by U937 cells may contribute to their adhesion to endothelial cells is suggested by the finding that antibodies to TSP partially inhibit adhesion to endothelial cell monolayers.

\section{MATERIALS AND METHODS}

U937 cells. A stock culture was obtained from the American Type Culture Collection (Rockville, MD). The cells were grown in suspension in RPMI-1640 medium containing $10 \%$ fetal bovine serum, 100 $\mathrm{U} / \mathrm{ml}$ of penicillin, and $100 \mu \mathrm{g} / \mathrm{ml}$ of streptomycin. Growth was at $37^{\circ} \mathrm{C}$ in an atmosphere of $5 \% \mathrm{CO}_{2} / 95 \%$ air. Cells were subcultured as required.

Endothelial cells. Rat pulmonary artery endothelial cells were used in certain experiments. These cells were obtained and characterized as described in a recent report [21]. The rat pulmonary artery endothelial cells were cultured using minimal essential medium of Eagle with Earle's salts, nonessential amino acids, $100 \mathrm{U} / \mathrm{ml}$ of penicillin, and $100 \mu \mathrm{g} / \mathrm{ml}$ of streptomycin (MEM) supplemented with $10 \%$ fetal bovine serum as culture medium. Growth was at $37^{\circ} \mathrm{C}$ in an atmosphere of $5 \% \mathrm{CO}_{2} / 95 \%$ air. These cells were used in experiments at passage $90-30$

Reagents. TSP, rabbit polyclonal antibodies to TSP, and a mouse monoclonal antibody to TSP were used in this study. TSP was purified from the supernatant fluid of thrombin-activated human platelets by heparin-Sepharose chromatography as described previously [22]. The purified TSP migrated as a single protein band with an apparent molecular weight of 160-170 kDa when examined by sodium dodecyl sulfate-polyacrylamide gel electrophoresis (SDS-PAGE) under reducing conditions. The rabbit polyclonal antibodies against TSP were purified by affinity chromatography on protein A-Sepha- 
rose. Specificity for TSP was confirmed by enzyme-linked immunosorbant assay (ELISA). The mouse monoclonal antibody, designated as A6.1 (IgG1) was obtained as an ascites fluid. Characteristics of this monoclonal antibody have been described in a previous report [23]. It is known to react with an epitope located in the $70-\mathrm{kDa}$ core of the TSP molecule.

Fibronectin, laminin, and rabbit polyclonal antibodies to fibronectin and laminin were also used in this study. Fibronectin and anti-fibronectin were obtained from Telios Pharmaceutical Co. (San Diego, CA). Laminin was obtained from Collaborative Research (Boston, MA), and anti-laminin was prepared in our laboratory and characterized as described previously [24]. Each antibody reacted with its respective ligand in ELISA but showed no cross-reactivity with the other ligand or with TSP. Normal mouse IgG1 was used as a negative control and a mouse monoclonal antibody to the CD18 component of the $\mathrm{CD} 11 \mathrm{~b} / \mathrm{CD} 18$ family was used as a positive control in the endothelial cell adhesion studies. This antibody (Clone IB4) was a generous gift from Dr. Sam Wright (Rockefeller University) [25]. OKM-5 antibody was obtained from Ortho Pharmaceutical Co. (Raritan, NJ).

Phorbol myristate acetate (PMA) was obtained from Sigma Chemical Co. (St. Louis, MO).

Biosynthetic labeling. U937 cells were plated in quadruplicate 100$\mathrm{mm}$ (diameter) petri dishes at $1 \times 10^{7}$ cells/dish and incubated for 1 day as control cells or in the presence of $100 \mathrm{nM}$ PMA. The cells were then washed and incubated for $30 \mathrm{~min}$ in methionine-free, serumfree, minimal essential medium (Flow Laboratories, Gaithersburg, $\mathrm{MD}$ ). The cells were again washed and incubated for an additional hour in the same medium containing $100 \mu \mathrm{Ci} /$ dish $\left[{ }^{35} \mathrm{~S}\right]$ methionine (1000-1400 $\mathrm{mCi} / \mathrm{mmol}$ ) (NEN, Boston, MA). After the 60 -min biosynthetic pulse, the cells in one control dish and one PMA-treated dish were washed and lysed as described below. The cells in the other two dishes were washed and incubated for a further $4 \mathrm{~h}$ in complete medium. The 1-h pulsed cells were lysed in a solution of phosphate-buffered saline (PBS) containing three detergents (1\% Triton X-100, $0.5 \%$ sodium deoxycholate, and $0.1 \%$ SDS; all obtained from Sigma) and protease inhibitors including $20 \mathrm{~m} M$ EDTA, $5 \mathrm{~m} M N$-ethylmaleimide, $2 \mathrm{~m} M$ phenylmethylsulfonyl fluoride (PMSF), and $10 \mu \mathrm{l} / 10 \mathrm{ml}$ of a protease inhibitor cocktail containing leupeptin $1 \mathrm{mg} / \mathrm{ml}$, antipain $1 \mathrm{mg} / \mathrm{ml}$, benzamidine $10 \mathrm{mg} / \mathrm{ml}$, and pepstatin $1 \mathrm{mg} / \mathrm{ml}$, as described by Ronnett et al. [26] in studies on the insulin receptor. All of the protease inhibitors were obtained from Sigma. The 4-h chase media were also supplemented with the detergent/protease inhibitor mixture by adding a one quarter volume of a fivefold concentrated solution. The cell lysates and chase media were frozen at $-80^{\circ} \mathrm{C}$, thawed, and clarified by ultracentrifugation $(37,000 \mathrm{~g}$ for $60 \mathrm{~min})$. Immunoreactive TSP was precipitated with a 1:100 dilution of the rabbit anti-TSP and protein A-Sepharose (Sigma) according to the protocol of Ruddon et al. [27]. The washed immunoprecipitates were divided in half and eluted with boiling $(5 \mathrm{~min}$ ) in twofold-concentrated mercaptoethanol. The immunoprecipitated material was fractionated on a $5 \%$ polyacrylamide gel employing the Laemmli system [28]. Radioactive bands were visualized by autoradiography with $\mathrm{En}^{3} \mathrm{Hance}$ (NEN), exposing the dried gels to X-ray film (Kodak XAR-2) for 2 days. In some experiments, anti-fibronectin was used in place of antiTSP. The immunoprecipitation was carried out in exactly the same manner.

Enzyme-linked immunosorbent assay (ELISA). ELISAs were performed to quantify the amount of TSP secreted into the culture medium by control and PMA-treated cells. Cells were plated at $3.5 \times 10^{5}$ cells per well in growth medium with or without PMA and incubated for 1 day. Following this, the cells were washed twice in serum-free RPMI-1640 medium and incubated for an additional $18 \mathrm{~h}$ in RPMI1640 medium supplemented with $200 \mu \mathrm{g} / \mathrm{ml}$ BSA (RPMI-BSA). The 18 -h culture medium was then harvested, clarified by low-speed centrifugation, and added to wells of a 96-well plate (Falcon Plastics, Oxnard, CA) from lots that had been prescreened for acceptability in ELISAs. We used $200 \mu \mathrm{l}$ per well and incubated the wells for $4 \mathrm{~h}$ at $37^{\circ} \mathrm{C}$. RPMI-BSA served as a negative control. Purified human platelet TSP (0.5-0.0005 $\mu$ g per well) was also added to the assay plate in the same buffer to serve as a standard. After the 4-h incubation, the culture medium from the cells and the control culture medium were removed from the wells and the ELISA was run exactly as described previously $[29 \mid$. The cells from which the culture medium was obtained were harvested with trypsin and counted. In some assays, antifibronectin was used in place of anti-TSP

Immunofluorescence. Control and PMA-treated cells were examined for anti-TSP binding by indirect immunofluorescence 1 day after treatment. At the time of staining, the culture medium was removed and the cells were gently washed three times in cold PBS. All subsequent steps were carried out at $4^{\circ} \mathrm{C}$. The cells were stained initially with a 1:20 dilution of the rabbit anti-TSP or normal rabbit serum $(45 \mathrm{~min})$ and then washed three times. They were then stained with a 1:50 dilution of fluorescein-conjugated swine anti-rabbit Ig( (45 min) obtained from Accurate Scientific and Chemical (Westbury, NY). Following three additional rinses in PBS, the coverslips were placed on glass slides and viewed immediately by standard fluorescence microscopic techniques.

Adhesion assay. U937 cell adhesion to purified extracellular matrix components (e.g., TSP, fibronectin, and laminin) and to endothelial cell monolayers was examined in this study. Matrix-coated plastic culture dishes were prepared by adding $20 \mu \mathrm{g}$ of the desired protein to each well of a 24-well dish in $0.5 \mathrm{ml}$ of MEM and incubating the dish for $2 \mathrm{~h}$ at $37^{\circ} \mathrm{C}$. Following this, the nonattached protein was removed and the dishes were incubated for $30 \mathrm{~min}$ with $0.5 \mathrm{ml}$ of MEM containing $10 \mathrm{mg} / \mathrm{ml}$ of bovine serum albumin. Control U937 cells and cells that had been treated with $100 \mathrm{n} M$ PMA for an appropriate period of time (normally 1 day) were harvested from culture, washed two times in MEM containing $200 \mu \mathrm{g} / \mathrm{ml}$ of bovine serum albumin (MEM-BSA), and added to the washed wells at $5 \times 10^{5}$ cells $/$ well. At various times later, the nonattached cells were removed and the wells were washed in MEM-BSA. The attached cells were removed with $0.25 \%$ trypsin and counted.

To assess adhesion to endothelial cells, wells of a 24 -well dish were seeded with $1 \times 10^{5}$ cells/well in growth medium and incubated overnight. The next day, the culture medium was removed from the monolayers and the cells were washed two times with warm MEM-BSA. Control and PMA-treated U937 cells were prepared as described above except that during the final day of incubation, $1 \mu \mathrm{Ci}$ of $\mathrm{Na}_{2}{ }^{51} \mathrm{CrO}_{4}$ per $1 \times 10^{6}$ cells was included in the culture medium. The ${ }^{51} \mathrm{Cr}$-labeled U937 cells were added to the endothelial cell monolayers at $5 \times 10^{5}$ cells per well in MEM-BSA. At various times later, the nonattached cells were removed and the monolayers were washed gently two times with warm MEM-BSA. After the final wash, the wells were trypsinized and the entire content of the well counted in a $\gamma$-scintillation counter. The total counts per minute (CPM) recovered from each well was compared to the number of CPM originally added to determine the percentage of adherent cells.

\section{RESULTS}

TSP production by control and PMA-stimulated U937 cells. In the first series of experiments control U937 cells and U937 cells incubated for 1 day with $100 \mathrm{nM}$ PMA in growth medium were examined for TSP production, secretion, and cell surface expression. Results from biosynthetic labeling/immunoprecipitation studies are shown in Fig. 1. Whole cell extract and culture fluid from control cells are shown in lanes 1 and 3 . Whole cell extract and culture fluid from the PMAtreated cells are shown in lanes 2 and 4 . A faint band can be seen at the 160- to $170-\mathrm{kDa}$ locus in lane 1 , consistent 


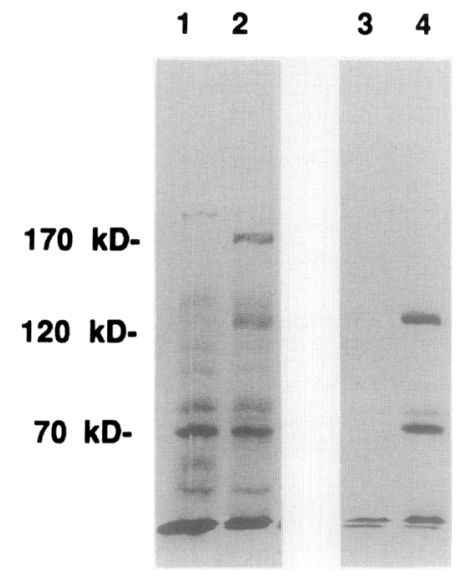

FIG. 1. Analysis by SDS-PAGE of TSP inmunoprecipitates from biosynthetically labeled U937 cells. Cell lysates from control and PMA-treated U937 cells immunoprecipitated with anti-TSP are shown in lanes 1 and 2, respectively. Chase media from the same cells immunoprecipitated with anti-TSP are shown in lanes 3 and 4, respectively.

with the molecular weight of TSP under reducing conditions. The corresponding band in lane 2 is much more intense. 'The culture fluid from the control cells, lane 3, shows no detectable immunoprecipitate with antibody to TSP. In contrast, the culture fluid from the PMAtreated cells (lane 4) shows two major anti-TSP-precipitable moieties. These two moieties have molecular weights of approximately 120 and $70 \mathrm{kDa}$, based on comparison of their migration with molecular weight markers. No detectable band corresponding to intact TSP (i.e., at $160-170 \mathrm{kDa}$ under reducing conditions) was seen. The presence of moieties at 120 and $70 \mathrm{kDa}$ is consistent with proteolysis of intact TSP. TSP is a proteolytically sensitive molecule and fragments of 120 and $70 \mathrm{kDa}$ are the major products seen after limited proteolysis [10].

Extracts from control and PMA-stimulated U937 cells were also immunoprecipitated with rabbit polyclonal anti-fibronectin. There was no detectable band in the 220- to 240-kDa region of the gel prepared with control cell extract or with extract from PMA-treated cells 1 day after treatment (not shown).

ELISAs were used to confirm the increased release of anti-TSP reactive moieties from PMA-treated U937 cells. For these experiments, U937 cells were cultured for 1 day in growth medium with or without PMA. Following this, they were washed and incubated for $18 \mathrm{~h}$ in RPMI-BSA. These culture fluids were then harvested and assayed for TSP and fibronectin by ELISA. The amount of TSP detected in the culture fluid from the PMA-treated cells was much higher than the amount detected in the control culture fluid (Table 1). In contrast, there was no measurable amount of fibronectin in the culture fluid from either control or PMA-treated U937 cells (Table 1).
Indirect immunofluorescence studies with anti-TSP were carried out to determine if there was also increased cell surface TSP expression following PMA treatment. Anti-TSP-stained control cells and cells treated for 1 day with PMA are shown in Fig. 2. There was significantly more staining of the treated cells than control cells. This was not seen when normal rabbit serum or anti-fibronectin was used in place of anti-TSP (not shown).

U937 cell adhesion to purified extracellular matrix components. Control and PMA-treated U937 cells were examined for attachment to immobilized TSP, fibronectin, and laminin. A small percentage of untreated cells attached to fibronectin but virtually none attached to TSP or laminin (Fig. 3). One day after treatment with $100 \mathrm{nM}$ PMA, the U937 cells demonstrated dramatically increased attachment to both TSP and fibronectin (Fig. 3). In the case of fibronectin, a significant percentage $(20-30 \%)$ of the attached cells also spread. There was no spreading on TSP and the cells formed large clumps on this substrate (not shown). In contrast to the results with TSP and fibronectin, PMA-treated U937 cells did not attach on laminin (Fig. 3). The adhesion response to TSP was specific in that pretreatment of the substrate with $50 \mu \mathrm{g}$ of rabbit polyclonal anti-TSP completely inhibited the interaction. The same antibody had no effect on cell attachment to fibronectin while rabbit polyclonal anti-fibronectin did not interfere with the attachment to TSP. We were also unable to block adhesion to TSP with commercially available OKM-5 monoclonal antibody (incubated with the cells for 15 min prior to addition of the cells to the substrate).

U937 cell adhesion to endothelial cells. Control and PMA-stimulated U937 cells were examined for adhesion to rat pulmonary artery endothelial cells. Very few of the untreated U937 cells (between $4-18 \%$, depending

\section{TABLE 1}

Immunoreactive TSP and Fibronectin in Culture Fluid from Control and PMA-treated U937 Cells

\begin{tabular}{lcc}
\hline \multirow{2}{*}{$\begin{array}{c}\text { Treatment } \\
\text { group }\end{array}$} & \multicolumn{2}{c}{ Amount produced $(\mathrm{ng} / 100 \mu \mathrm{l})$} \\
\cline { 2 - 3 } & TSP & Fibronectin \\
\hline $\begin{array}{l}\text { Control } \\
\text { PMA-treated }\end{array}$ & $\begin{array}{c}<5 \\
25 \pm 3\end{array}$ & $<5$ \\
\hline
\end{tabular}

Note. Control U937 cells and PMA-treated U937 cells $\left(1 \times 10^{6} / \mathrm{ml}\right)$ were incubated in RPMI-1640 medium containing $10 \%$ fetal bovine serum for 1 day. The cells were then washed two times and incubated in RPMI-BSA for $18 \mathrm{~h}$. The 18 -h culture fluids were harvested and analyzed for TSP and fibronectin by ELISA. Values were obtained directly from standard curves. Values shown represent averages \pm differences between individual values and averages based on duplicate samples in a single experiment. The experiment was repeated five times with similar results. 

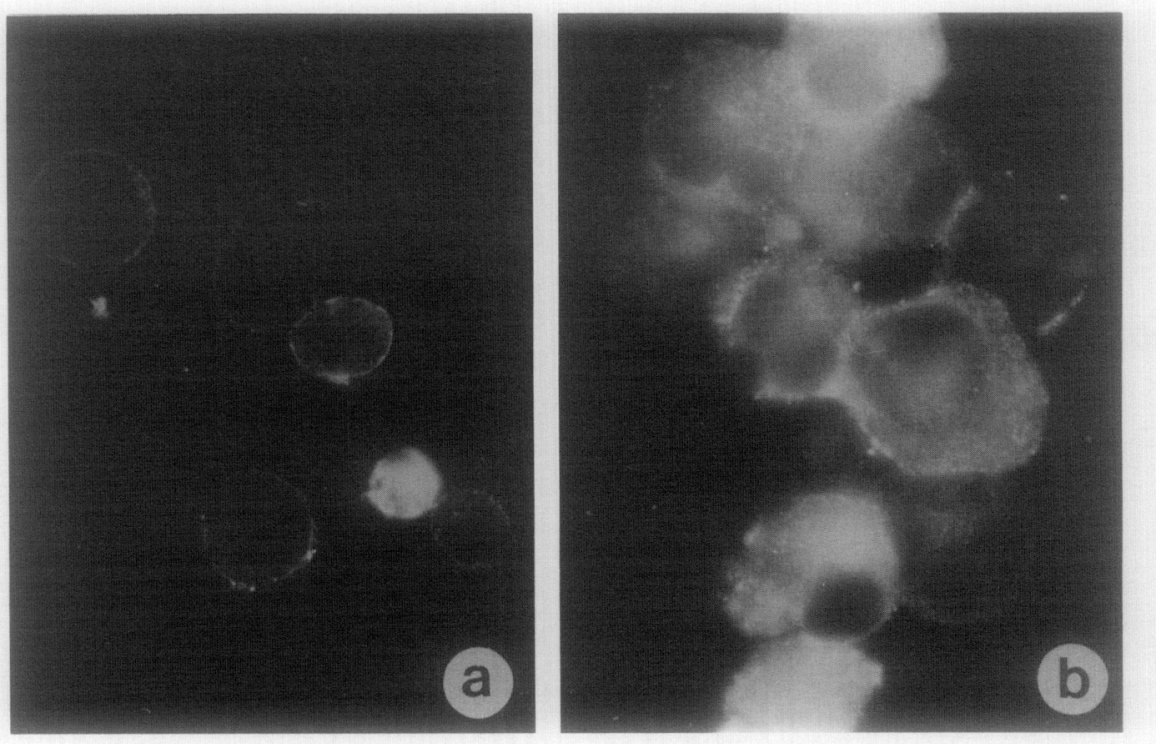

FIG. 2. Immunofluorescence staining of control (a) and PMA-treated U937 cells (b) with anti-TSP in the viable state. Photographs are 1 min exposures. $\times 400$.

on the experiment) attached to the endothelial cells. In contrast, a large percentage of the PMA-stimulated U937 cells attached to the endothelial cell monolayers. Attachment was seen as early as $30 \mathrm{~min}$ after plating and was maximal by $4 \mathrm{~h}$. In order to determine if TSP plays a role in U937 cell adhesion to endothelial cells, mouse monoclonal antibodies to TSP were used in blocking experiments. For these experiments, control and PMA-treated U937 cells were harvested from culture, washed, and incubated with the appropriate antibody for $15 \mathrm{~min}$ in assay buffer (MEM-BSA). The cells along with the antibodies were then added to the endothelial cell monolayers and the assay carried out in the normal manner. The monoclonal antibody to TSP significantly inhibited attachment of PMA-treated U937 cells as compared to the negative control antibody (Table 2). However, anti-TSP proved to be much less effective than the antibody directed against CD18 (Table 2).

\section{DISCUSSION}

TSP production by monocytes has been examined in two previous studies. In the first, Jaffe et al. [17] demonstrated that human peripheral blood monocytes and mouse resident peritoneal macrophages synthesized TSP and secreted the synthesized moiety into the culture medium. Most of the secreted TSP appeared to be intact, as indicated by autoradiography of biosynthetically labeled/immunoprecipitated extracts. It was reported in this study that TSP could not be detected on the cell surface or in the cell layer by immunofluorescence. In a later study we also showed that human monocytes synthesize TSP and secrete the intact molecule into the culture medium [18]. Consistent with the ob- servations of Jaffe et al. [17], we did not see cell surface TSP by immunofluorescence when the cells were examined immediately after plating. However, when the cells were examined after they had been in culture for $18 \mathrm{~h}$ cell surface staining for TSP was clearly evident. Our study also suggested that TSP may serve in the interaction of human peripheral blood monocytes with human squamous carcinoma cells. This was based on the observation that antibodies to TSP partially inhibited monocyte killing of human squamous carcinoma cells and on the observation that squamous epithelial cells which expressed high levels of TSP receptors were more sensitive to killing by monocytes than cells which did not [18].

In the present study we examined TSP production and cell surface expression by U937 cells. The U937 line was originally derived from a histiocytic lymphoma and demonstrates characteristics of monocytes [19]. U937 cells can be induced by a variety of agents, including PMA, to differentiate into mature macrophage-like cells [20]. Consistent with previous findings with human peripheral blood monocytes, which did not express surface TSP immediately upon isolation but which did after incubation in vitro for $18 \mathrm{~h}[17,18]$, unstimulated U937 cells were deficient in surface TSP but stained brightly with anti-TSP after treatment with PMA. With both normal peripheral blood monocytes and U937 cells, therefore, TSP expression is correlated with cellsubstrate adhesion in vitro. It should be noted that mouse resident peritoneal macrophages have also been shown to synthesize TSP [17]. Thus, TSP production appears to reflect transition from the monocytoid state to macrophage-like cells.

In addition to stimulating 'ISP biosynthesis, PMA 

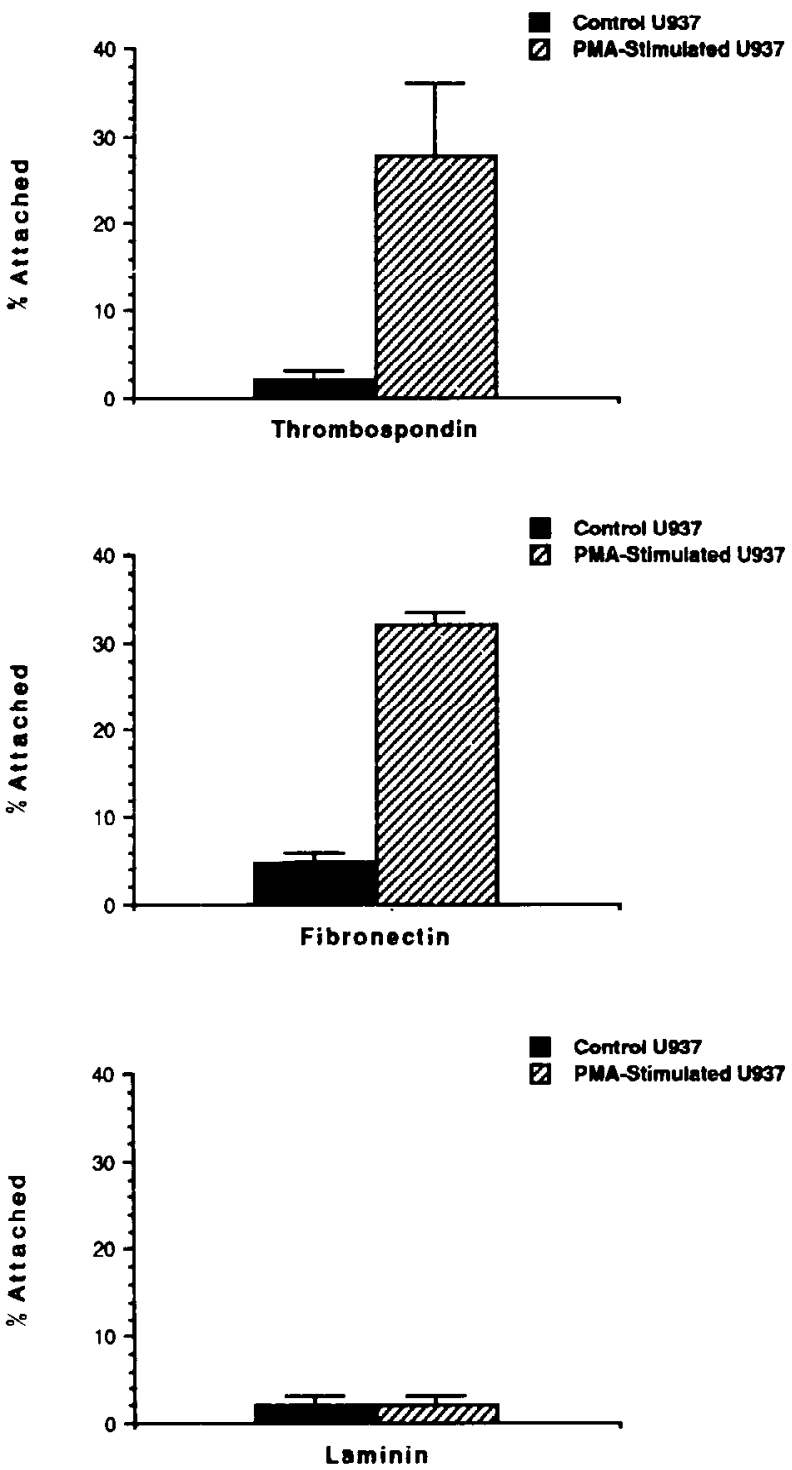

FIG. 3. Attachment of control and PMA-treated U937 cells to plastic culture dishes coated with $20 \mu \mathrm{g}$ of TSP, fibronectin, and laminin. Values shown represent the average percentage of cells attached to matrix-coated dishes \pm differences between individual values and averages based on duplicate samples in a single experiment. The experiment was repeated three times with similar results.

treatment of U937 cells also resulted in increased adhesion to TSP. This suggests that TSP receptor expression is up-regulated concomitantly with induction of TSP synthesis. Coordinated induction of TSP biosynthesis and TSP binding is not unique to these cells. The induction of TSP synthesis in squamous epithelial cells is also accompanied by increased TSP binding and increased cell-substrate adhesion [11, 12]. Additionally, past studies have shown that with other extracellular matrix molecules such as fibronectin, induction of ligand synthesis is accompanied by up-regulation of receptor expression [30-32]. Thus, coregulation of extracellular matrix synthesis and expression of their cell surface receptors may be a common occurance. At present, the nature of the TSP-binding moieties up-regulated on the U937 cells by PMA is not known. At least one moiety which has been reported to serve as a TSP receptor on monocytes (i.e., CD36, the antigen for commercially available OKM5 monoclonal antibody) [33] is also expressed on U937 cells [33] and has been reported to be up-regulated following PMA treatment [34]. Perhaps increased expression of this moiety accounts for the increased adhesiveness that follows PMA treatment. We were unable, however, to demonstrate significant inhibition with antibody directed against this ligand and several additional TSP-binding moieties have been identified on other cells. Among these are a member of the integrin family [35], a heparan sulfate proteoglycan [36], and a glycolipid [37]. Additional studies will be necessary to determine if any of these structures are also influenced by PMA and if any of these receptors are critical to U937 cell adhesive functions.

A goal of this work was to determine if TSP plays a role in U937 cell adhesion to endothelial cells. Previous studies have shown a role for TSP in monocyte-platelet interaction [34] and our recent study suggested that TSP may be involved in monocyte killing of human squamous carcinoma cells [18]. In the present study we used a murine monoclonal antibody to TSP to block adhesion to rat pulmonary artery endothelial cells. Attachment of PMA-activated U937 cells to endothelial cells in the presence of this antibody was reduced by approximately $25 \%$. These data suggest that TSP contributes to but is not the major surface ligand mediating adhesion of activated U937 cells to the endothelium. In the same series of experiments as those described above, we found that antibodies to TSP also inhibited human peripheral blood monocyte adhesion to the rat pulmonary artery endothelial cells by approximately

TABLE 2

Inhibition of U937 Cell $\Lambda$ dhesion to Rat Pulmonary Artery Endothelial Cells

\begin{tabular}{cc}
\hline Treatment group & Percent attached \\
\hline Control U937 & $18 \pm 1$ \\
PMA-treated U937 & \\
No antibody & $53 \pm 1$ \\
anti-TSP & $41 \pm 1$ \\
anti-CD18 & $12 \pm 1$ \\
IgG1 & $54 \pm 2$ \\
\hline
\end{tabular}

Note. Control or PM $\Lambda$-treated U937 cells were incubated with the appropriate antibody ( $50 \mu \mathrm{l}$ of antibody incubated with $200 \mu \mathrm{l}$ of cell suspension) for $15 \mathrm{~min}$ and then the cells with antibody were added to the endothelial monolayers. Cell attachment was determined $2 \mathrm{~h}$ later. Values shown represent averages \pm standard deviations based on triplicate samples in a single experiment. The experiment was repeated two times with similar results. 
$25 \%$ (unpublished observation). Thus, TSP may play a role in the adhesive interactions of normal monocyte as well as U937 cells with the endothelium.

This study was supported by grant IM-432 from the American Cancer Society and by grant CA39064 from the USPHS. Dr. T. Wang was a visiting scholar from the China-Japan Friendship Hospital in Beijing, PRC.

\section{REFERENCES}

1. McPherson, J., Sage, H., and Bornstein, P. (1981) J. Biol. Chem. 256, 1130.

2. Raugi, G. J., Mumby, S. M., Abbott-Brown, D., and Bornstein, P. (1982) J. Cell. Biol. 95, 351.

3. Jaffe, E. A., Ruggiero, J. T., Leung, L. L. K., Doyle, M. J., Mckeown-Longo, P. J., and Mosher, D. F. (1983) Proc. Natl. Acad. Sci. USA 80, 990.

4. Sage, H., Farin, F. M., Striker, G. E., and Fisher, A. B. (1983) Biochemistry 22, 2148.

5. Varani, J., Dixit, V. M., Fligiel, S. E. G., McKeever, P. E., and Carey, T. E. (1986) Exp. Cell. Res. 167, 376.

6. Varani, J., Riser, B. L., Hughes, L. A., Carey, T. E., Fligiel, S. E. G., and Dixit, V. M. (1989) Clin. Exp. Metast. 7, 265.

7. Varani, J., Carey, T. E., Fligiel, S. E. G., McKeever, P. E., and Dixit, V. (1987) Int. J. Cancer 39, 397.

8. Roberts, D. D., Sherwood, J. A., and Ginsburg, V. (1987) J. Cell Biol. 104, 131.

9. Tuszynski, G. P., Rothman, V. L., Murphy, A., Seigler, K., Smith, S., Smiths, J., Karczewski, J., and Knudsen, K. A. (1987) Science 236, 1570.

10. Varani, J., Nickoloff, B. J., Riser, B. L., Mitra, R. S., O'Rourke, K., and Dixit, V. M. (1987) J. Clin. Invest. 81, 1537.

11. Riser, B. L., Varani, J., O'Rourke, K., and Dixit, V. M. (1988) Exp. Cell Res. 174, 319.

12. Riser, B. L., Varani, J., Nickoloff, B. J., Mitra, R. S., and Dixit, V. M. (1990) Dermulologica 180,60.

13. Wight, T. N., Raugi, G. J., Mumby, S. M., and Bornstein, P. (1985) .J. Histochem. Cytochem. 33, 299

14. Majack, R. A., Cook, S. C., and Bornstein, P. (1985) J. Cell Biol. $101,1059$.

15. Majack, R. A., Cook, S. C., and Bornstein, P. (1986) Proc. Natl. Acad. Sci. USA 83, 9050.
16. Phan, S. H., Dillon, R. G., McGarry, B. M., and Dixit, V. M. (1989) Biochem. Biophys. Res. Commun. 163, 56.

17. Jaffe, E. A., Ruggiero, J. 'T., and Falcone, D. J. (1985) Blood 65, 79 .

18. Riser, B. L., Mitra, R., Perry, D., Dixit, V. M., and Varani, J. (1989) Cancer Res. 49, 6123.

19. Sundstrom, C., and Nilsson, K. (1976) Int. J. Cancer 1 7, 565.

20. Wiederhold, M. D., Anderson, K. M., and Harris, J. E. (1988) Biochim. Biophys. Acta 959, 296.

21. Phan, S. H., Gannon, D. E., Varani, J., Ryan, U. S., and Ward, P. A. (1989) Am. J. Path. 134, 1201.

22. Dixit, V. M., Grant, G. A., Santoro, S. A., and Frazier, W. A. (1984) J. Biol. Chem. 259, 10,100.

23. Dixit, V. M., Haverstick, D. M., O'Rourke, K. M., Hennessy, S. W., Grant, G. A., Santoro, S. A., Frazier, W. A. (1985) Proc. Natl. Acad. Sci. USA 82, 3472.

24. Schuger, L., O'Shea, S., Rheinheimer, J., and Varani, J. (1990) Deu. Biol. 137, 26.

25. Wright, S., Rao, P., Van Voorhis, W., Craigmyle, L., Iida, K., Talle, M., Westberg, E., Goldstein, G., and Silverstein, S. (1983) Proc. Natl. Acad. Sci. USA 80, 5699.

26. Ronnett, G. V., Knutson, V. P., Kohnski, R. A., Simpson, T. L., and Lane, M. D. (1984) J. Biol. Chem. 259, 4566.

27. Ruddon, R. W., Hanson, C. A., and Addison, N. J. (1979) Proc. Natl. Acad. Sci. USA 76, 5173.

28. Laemmli, U. K. (1970) Nature (London) 227, 680 .

29. Varani, J., Lovett, E. J., McCoy, J. P., Shibata, S., Maddox, D., Goldstein, I. J., and Wicha, M. (1983) Am. J. Pathol. 111, 27.

30. Ignotz, R. A., and Massague, J. (1987) Cell 51, 189.

31. Roberts, C. J., Birkenmeier, T. M., McQuillan, J. J., Akiyama, S. K., Yamada, S. S., Chen, W-T., Yamada, K. M., and McDonald, J. A. (1988) J. Biol. Chem. 263, 4586.

32. Varani, J., and Chakrabarty, S. (1990) J. Cell. Physiol. 113, 116.

33. Silverstein, R. L., Asch, A. S., and Nachman, R. L. (1989) J. Clin. Invest. 84, 546.

34. Talle, M. A., Rao, P. E., Westberg, E., Allegan, N., Makowski, M., Mittler, R. A., and Goldstein, G. (1983) Cell. Immunol. 78, 83.

35. Lawler, J., Weinstein, R., and Hynes, R. O. (1988) J. Cell. Biol. 107, 2351.

36. Murphy-Ullrich, J. E., and Mosher, D. F. (1987) J. Cell. Biol. 105, 1603.

37. Roberts, D. D., Haverstick, D. M., Dixit, V. M., Frazier, W. A., Santoro, S. A., and Ginsburg, V. (1985) J. Biol. Chem. 260, 9405.

Received November 6, 1990

Revised version received February 25, 1991 